\section{Protocorm-like Bodies Initiation from Root Tips of Cyrtopodium paranaense (Orchidaceae)}

\author{
Wei-Ling Guo \\ Department of Horticulture, National I-Lan University, Yilan 26047, Taiwan
}

\begin{abstract}
Yao-Chien Alex Chang
Department of Horticulture, National Taiwan University, Taipei 10617, Taiwan
\end{abstract}

\section{Chien-Yuan Kao ${ }^{1}$}

Department of Horticulture, National I-Lan University, Yilan 26047, Taiwan

Additional index words. root tip culture, somatic embryogenesis, in vitro propagation, indole3-acetic acid, thidiazuron

\begin{abstract}
Cyrtopodium paranaense is a tropical terrestrial orchid, which propagates mainly through sexual seed germination. In this study, we document the asexual morphogenesis of the root tip to protocorm-like body (PLB) conversion in Cyrtopodium paranaense. Protocorm-like bodies sporadically developed from root tips of flask-grown seedlings in the absence of any exogenous plant growth regulators (PGRs). The compact PLBs ultimately gave rise to normal plantlets. Histological observations revealed that the root cap became dissociated from the root apex at an early stage followed by dispersed extension of root vascular strands into nascent PLBs. Protocorm-like bodies also developed from the root central stele tissue. In root tip segment cultures, PLBs were not formed without providing PGRs but were efficiently formed from root tips in Murashige and Skoog (MS) medium supplemented with $10.2 \mu \mathrm{M}$ indole-3-acetic acid (IAA) and 9.0 $\mu$ M thidiazuron (TDZ). Both IAA and TDZ promoted the formation of PLBs; however, TDZ did not induce PLB formation in the absence of IAA, indicating a synergistic effect of the two PGRs. Protocorm-like bodies were proliferated and subsequently plants regenerated in PGR-free MS medium. Root tip culture may be used as an alternative method for the propagation of Cyrtopodium paranaense.
\end{abstract}

There are more than 30 species of Cyrtopodium distributed in south-most Florida and Central and South America (Pridgeon, 1998). The generic name Cyrtopodium means "curved little foot" for the shape of the column in the center of the flower. Cyrtopodium plants such as Cyrtopodium cardiochilum have been used for anti-inflammatory purposes and puncture wounds by Brazilian inlanders but are threatened by urbanization in Brazil (Barreto and Parente, 2006; Menezes, 1995a, 1995b). Cyrtopodium paranaense is a tropical terrestrial species with thick pseudobulbs and racemes that rise from the developing shoot. In its natural propagation, $C$. paranaense is mainly through sexual (i.e., gene recombination) pollinated seed germination. Culture media for growth of seed-derived protocorms in $C$. paranaense have been surveyed (Rego-Oliveira and Faria, 2005). However, there are no reports on vegetative protocorm-like body (PLB) induction or in vitro regeneration of $C$. paranaense.

A variety of explants have been used in many laboratories for clonal propagation of

Received for publication 10 Feb. 2010. Accepted for publication 16 May 2010.

${ }^{1}$ To whom reprint requests should be addressed; e-mail cykao@niu.edu.tw. orchids, producing millions of low-cost orchid plantlets throughout the world (Chen and Chang, 2006; Chugh et al., 2009; Ernst, 1994; Park et al., 2003; Teng et al., 1997). However, a number of problems have restricted the choice of explants, including phenolic exudation, limited numbers of meristems, the difficulty to induce PLBs, and somaclonal variation (Chugh et al., 2009; Sánchez, 1988). Although root tips of orchids are considered recalcitrant as explants in tissue culture, the formation of PLBs by embryogenesis occurs in certain orchids such as Oncidium and Doritaenopsis (Kerbauy, 1984; Park et al., 2003).

In the present study, we investigated the effects of indole-3-acetic acid (IAA) and thidiazuron (TDZ) on inducing PLB formation from excised root tips of aseptically grown seedlings of $C$. paranaense. The root tip-PLB conversion was monitored through histological sections at different develop-

\section{Materials and Methods}

Seed germination and explant preparation. Seeds of Cyrtopodium paranaense used in the study were obtained from a ripened capsule. The capsule was surface-sterilized in $70 \%$ ethanol for $30 \mathrm{~s}$ followed by a $0.6 \%$ mental stages. solution of sodium hypochlorite containing $0.1 \%$ Tween 20 (Sigma, St. Louis, MO) for $10 \mathrm{~min}$ and triple-rinsed in sterile distilled water. The sterilized capsule was placed in a laminar flow hood for $10 \mathrm{~min}$ until its surface desiccated and then dissected longitudinally. The seeds were spread on the surface of autoclaved basal culture medium in a $500-\mathrm{mL}$ flask. The medium consists of $100 \mathrm{~mL}$ of Murashige and Skoog (MS) salts (Murashige and Skoog, 1962) with $2 \mathrm{~g} \cdot \mathrm{L}^{-1}$ Bacto-tryptone (BD Biosciences, Franklin Lakes, NJ), $35 \mathrm{~g} \cdot \mathrm{L}^{-1}$ sucrose, and solidified with $10 \mathrm{~g} \cdot \mathrm{L}^{-1}$ Bacto-agar (BD Biosciences). The $\mathrm{pH}$ of all culture media was adjusted to 5.4 before autoclaving at $1.1 \mathrm{~kg} \cdot \mathrm{cm}^{-2}$ for 20 min. Seed germination was carried out in a controlled environment at 25 to $27^{\circ} \mathrm{C}$ with 16-h light from a cool-white fluorescent lamp at $30 \mu \mathrm{mol} \cdot \mathrm{m}^{-2} \cdot \mathrm{s}^{-1}$. Root tips $(\approx 1 \mathrm{~cm}$ long) were dissected from the in vitro-cultured seedlings that were 3 months old ( 5 to $7 \mathrm{~cm}$ in height) and used for the induction of PLBs.

Induction of protocorm-like bodies from excised root tip segments. Five root-tip segments $(\approx 1 \mathrm{~cm})$ were placed in a 6 -cm petri dish containing $10 \mathrm{~mL}$ basal culture medium supplemented with different combinations of four concentrations of IAA (Sigma) $(0$, 2.5, 5.1, and $10.2 \mu \mathrm{M})$ and TDZ (Sigma) $(0$, $2.3,4.5$, and $9.0 \mu \mathrm{M}$ ) in a complete factorial arrangement. Each treatment consisted of three petri dishes (each included five root tips) replications. All cultures were maintained in a dark culture room at 25 to $27{ }^{\circ} \mathrm{C}$. After 3 weeks of culture, root-tip explants were removed from the petri dishes and evaluated in terms of PLB formation at the tip. Percentage of PLB conversion in each petri dish and diameters of the formed PLBs were measured. This experiment used a completely randomized design; a petri dish is considered as an experimental unit. Data collected from each petri dish were averaged and considered as an observation. Data in percentage were transformed by angular transformation (Steel et al., 1997). Twoway analysis of variance was carried out using CoStat 6.1 (CoHort Software, Monterey, CA). Mean separations were conducted using the least significance difference test at $P \leq 0.05$.

Histological observation. Root tip samples were taken $0,16,25$, and $35 \mathrm{~d}$ after culture and fixed in a solution containing five parts formalin, five parts acetic acid, and 90 parts $50 \%$ ethyl alcohol at room temperature. Samples were dehydrated through a tertiary butyl alcohol series and embedded in Paraplast (Johansen, 1940). Serial 8- to $10-\mu \mathrm{m}$ sections were cut using a microtome (MIC506; Lipshaw Manufacturing Co., Detroit, MI). Longitudinal sections made from base to apex $\approx 1 \mathrm{~cm}$ long were stained with hematoxylin, safranin, and fast green by the method of Foster as modified by Schneider (1981). The sections were then examined under a photomicroscope (SMZ1000; Nikon, Tokyo, Japan), and photomicrographs were taken with a digital camera (COOLPIX 5400; Nikon). 


\section{Results and Discussion}

During in vitro culture of $C$. paranaense seedlings on a MS medium, direct PLB formation was sporadically observed in submerged root apices (Fig. 1A) and in non-apical regions (Fig. 1B). These PLBs regenerated plantlets with maternal roots still attached (Fig. 1C-D) and were morphologically similar to maternal plants and successfully acclimatized into soil. However, no PLB formation was observed when excised root tips or root segments were cultured in the same medium. It was essential that the original $C$. paranense nurse plant remains intact during PLB induction when no additional plant growth regulator (PGR) was provided. The fact that PLBs formed only at root apices and in mature regions of in vitro seedlings (Fig. 1) but not in excised root tips or root segments underscores the role of the intact $C$. paranaense plant for PLB induction.

Various concentrations of IAA and TDZ added in basal culture medium were investigated for their ability to induce PLB on excised root tips. Results of analysis of variance indicated that both IAA and TDZ promoted PLB formation and there was a significant interaction between the two PGRs (Table 1). When IAA was used as the sole PGR, root-tip explants with PLB formation only were obtained at $10.2 \mu \mathrm{M}$. On the other hand, no PLBs were produced regardless of concentration when TDZ was tested alone. However, the combination of IAA and TDZ greatly enhanced PLB formation. On the media supplemented with $10.2 \mu \mathrm{M}$ IAA or with a combination of 5.1 $\mu \mathrm{M}$ IAA and 9.0 $\mu \mathrm{M}$ TDZ, the excised root tips developed into larger PLBs with diameter of 1.3 to $1.4 \mathrm{~mm}$ after 3 weeks. These data indicate that there is a synergistic effect between auxin and cytokinin (Table 1). Different PGRs have been reported to enhance PLB induction from the excised root tips of several orchid species (Churchill et al., 1972; Kerbauy, 1984; Park et al., 2003; Sánchez, 1988; Stewart and Button, 1978). Depending on their concentrations, cytokinin was found more effective in the induction of root tip PLBs than auxin. In this experiment, however, higher concentration of IAA alone but not TDZ induced PLBs from root tips of $C$. paranaense. By contrast, in Catasetum fimbriatum and Catasetum pileatum, the excised root apices formed PLBs in MS medium without PGRs (Colli and Kerbauy, 1993; Kraus and Monteiro, 1989). This indicates that the requirement for PGR in medium for root tip PLB formation is speciesdependent.

In this study, we found that root tip explant of $C$. paranaense stopped its elongation and formed a clear globular structure in the apical region in the presence of IAA and TDZ; whereas in medium devoid of IAA and TDZ, the root tip explants only survived and notably increased in length (Fig. 2). These data indicate that the inhibition of root tip elongation and meristematic cell division in the root apical region is very important for root tip-PLB conversion of $C$. paranaense. Further
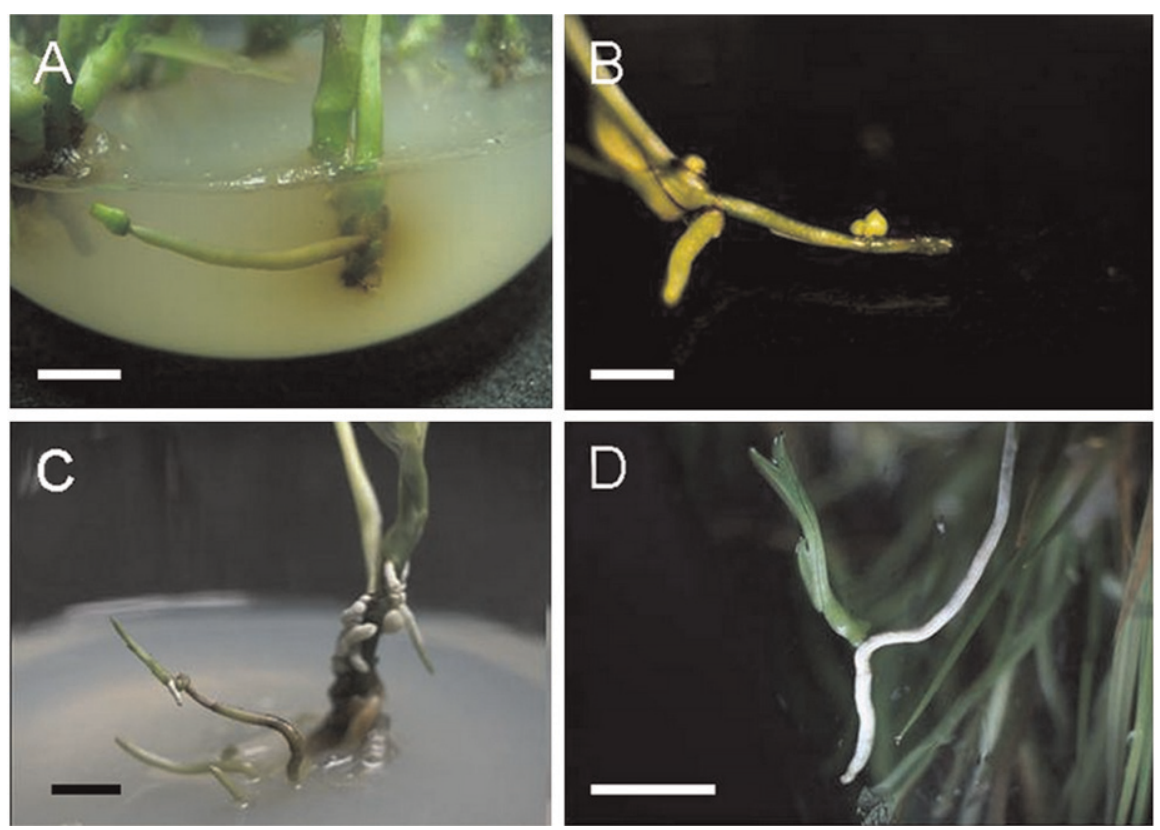

Fig. 1. Root tip- and central stele-derived protocorm-like body (PLB) and subsequent plantlets of Cyrtopodium paranaense in Murashige and Skoog medium without plant growth regulator. (A) PLB formed from the root tip of aseptically grown seedling; (B) a developing PLB formed from central stele tissue of an aseptically grown seedling; (C) rooted plantlet from root tip PLB while connecting to the maternal plant; (D) well-developed plantlet from a root central stele-derived PLB of maternal plant. Bars $=10 \mathrm{~mm}$.

Table 1. Effects of concentrations of indole-3-acetic acid (IAA) and thidiazuron (TDZ) on formation of protocorm-like bodies (PLBs) from excised root tip of Cyrtopodium paranaense. ${ }^{\mathrm{z}}$

\begin{tabular}{|c|c|c|c|}
\hline IAA concn $(\mu \mathrm{M})$ & $\begin{array}{l}\text { TDZ concn } \\
(\mu \mathrm{M})\end{array}$ & $\begin{array}{l}\text { Explant with PLB } \\
\text { formation }(\%)\end{array}$ & $\begin{array}{l}\text { Diam of PLBs } \\
(\mathrm{mm})^{\mathrm{x}} \\
\end{array}$ \\
\hline \multirow[t]{4}{*}{0} & 0 & $0 \mathrm{e}^{\mathrm{y}}$ & NA \\
\hline & 2.3 & $0 \mathrm{e}$ & NA \\
\hline & 4.5 & $0 \mathrm{e}$ & NA \\
\hline & 9.0 & $0 \mathrm{e}$ & NA \\
\hline \multirow[t]{4}{*}{2.5} & 0 & $0 \mathrm{e}$ & NA \\
\hline & 2.3 & $0 \mathrm{e}$ & NA \\
\hline & 4.5 & $13 \mathrm{~d}$ & $1.1 \mathrm{~b}$ \\
\hline & 9.0 & $20 \mathrm{~d}$ & $1.1 \mathrm{~b}$ \\
\hline \multirow[t]{4}{*}{5.1} & 0 & $0 \mathrm{e}$ & NA \\
\hline & 2.3 & $40 \mathrm{c}$ & $1.1 \mathrm{~b}$ \\
\hline & 4.5 & $80 \mathrm{~b}$ & $1.1 \mathrm{~b}$ \\
\hline & 9.0 & $80 \mathrm{~b}$ & $1.3 \mathrm{a}$ \\
\hline \multirow[t]{4}{*}{10.2} & 0 & $80 \mathrm{~b}$ & $1.3 \mathrm{a}$ \\
\hline & 2.3 & $100 \mathrm{a}$ & $1.3 \mathrm{a}$ \\
\hline & 4.5 & $80 \mathrm{~b}$ & $1.4 \mathrm{a}$ \\
\hline & 9.0 & $100 \mathrm{a}$ & $1.4 \mathrm{a}$ \\
\hline \multicolumn{4}{|l|}{ Significance } \\
\hline IAA concn (I) & & $* * *$ & $* * *$ \\
\hline TDZ concn $(\mathrm{T})$ & & $* * *$ & NS \\
\hline $\mathrm{I} \times \mathrm{T}$ & & $* * *$ & NS \\
\hline
\end{tabular}

${ }^{\mathrm{z}}$ Data were collected 3 weeks after incubation.

y Means followed by a different letter in the same column are significantly different at $P \leq 0.05$ by least significant difference test $(\mathrm{n}=3)$.

${ }^{x}$ Data excluded explants without PLBs formation and statistical analysis were only conducted to treatments with occurrences of PLB formation.

NS, ***Nonsignificant or significant at $P \leq 0.001$.

$\mathrm{NA}=$ not applicable for no PLB was regenerated.

differentiation of these PLBs proceeded normally into plantlets in PGR-free basal medium.

Histological sections showed the relationship of PLBs to their originating maternal roots. Similar to the histology of terrestrial orchids roots (Arditti, 1992), the root apex region of in vitro $C$. paranaense seedlings consisted of several cell layers (Fig. 3A).
Below the root cap lay the promeristem, protoderm, ground meristem, and procambial tissues. These tissues joined constrictively to quiescent center under the restraint of the root cap. Excised root apices cultured on MS medium containing $10.2 \mu \mathrm{M}$ IAA displayed substantial anatomical modifications after 2 weeks (Fig. 3B). At this stage, the small 


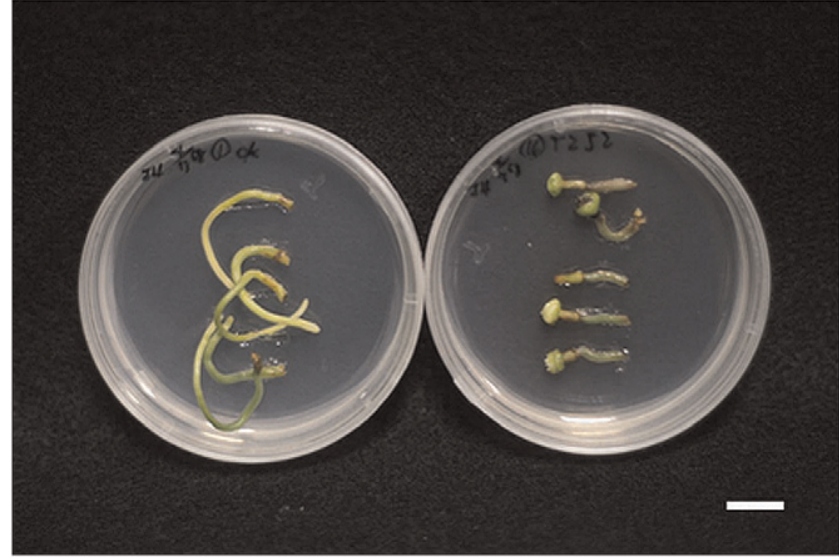

Fig. 2. Formation of protocorm-like bodies (PLBs) from excised root tip explants cultured in Murashige and Skoog (MS) medium. Formation of PLB from root tip explants (right) cultured in MS medium containing $10.2 \mu \mathrm{M}$ indole-3-acetic acid and $9.0 \mu \mathrm{M}$ thidiazuron in comparison with no PLBs forming (left) but growing longer with no plant growth regulator added to the medium. Bar $=10 \mathrm{~mm}$.
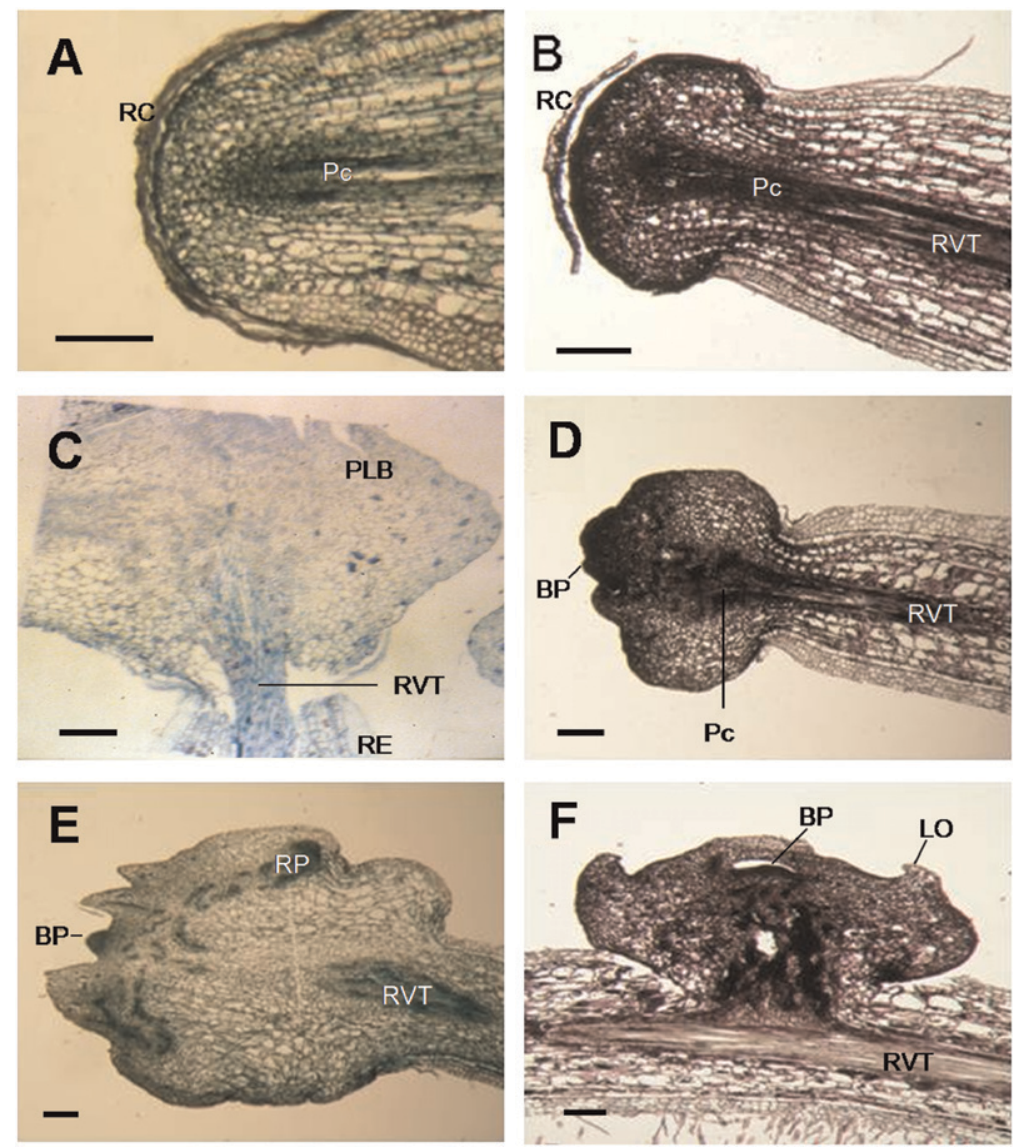

Fig. 3. Histological sections from the root tip and central stele of Cyrtopodium paranaense during protocorm-like body (PLB) formation. (A) Longitudinal section of root apex used as the typical explants, showing a root tip with procambium (Pc) and surrounded by root cap (RC); (B) after $16 \mathrm{~d}$ of incubation, the root cap (RC) was disorganized and globular expansion was developed on the end of root vascular tissue (RVT); (C) nascent root tip PLB containing dispersed vascular strands extended from root explant (RE); (D) after $25 \mathrm{~d}$ of incubation, PLB formation with meristematic cells in apical bud primordium (BP); (E) after $35 \mathrm{~d}$, well-defined bud (BP) and root primordia (RP) were visible in the anterior and middle regions of the PLB; (F) nascent PLB originating from vascular tissue (RVT) of the root central stele of an intact seedling with bud primordium (BP) and leaf like organ (LO) visible. Bars $=0.25 \mathrm{~mm}$.

meristematic cells divided and resulted in the earliest morphological sign of globular expansion at the root tip. This globular expansion increased in size as a result of division

and enlargement to become a PLB. A single PLB was induced per morphogenic responded root tip. During these root apex-PLB conversions, the root caps became disorganized and disconnected from the tip (Fig. 3B). Disappearance of the root cap was also observed in orchid Catasetum pileatum (Kraus and Monteiro, 1989), and its relationship to the mitotic activity of meristematic cells underneath was described in Zea mays and Pisum sativum (Barlow and Hines, 1982). Histological observations also reveal that the constricted vascular strands in normal root apex (Fig. 3A) were dispersed and extended into the globular expansion (Fig. 3C). This dispersed vascular system in early PLB formation seems to support further PLB enlargement but apparently independent of its differentiation in later stages. The PLB formation from root tips in C. paranaense, particularly the existence of vascular connections between early PLBs and explants, is different from the developmental patterns of single cell-originated somatic embryo in other orchids (Kerbauy, 1984; Park et al., 2003). Occasionally, after root tip PLBs mature, the dispersed vascular system of the root tip coordinates into a normal constricted pattern again and resumes as normal maternal root (data not shown). With increased development, the PLBs were already well defined with bud primordium appearing at the top and root primordium at the middle regions of the PLBs (Fig. 3D-E).

PLBs and their subsequent development were also noticed from non-apical regions of the root in flask-grown $C$. paranaense seedlings (Fig. 1D). Anatomical sections clearly showed that PLBs originated from the exterior of the root central stele, protruding through the cortex and velamen (Fig. 3F). However, attempts to induce PLBs from mature roots of in vitro seedlings and excised root segments by mechanical injury and PGR treatment were ineffective.

In conclusion, the present results clearly showed $C$. paranaense PLB initiation from root apices and root central stele of in vitro seedlings in MS medium and from excised root tip in medium with addition of PGRs. From histological analysis of developmental phases, the closed vascular system normally observed in the root apical region progressively developed into a dispersed pattern and extended into nascent PLBs. These PLBs subsequently differentiate their own closed vascular system to separate from originating maternal root. Our results clearly indicate that asexual PLBs initiated from root tips and root central stele tissues of $C$. paranaense are dependent on root vascular tissue at its early development.

\section{Literature Cited}

Arditti, J. 1992. Fundamentals of orchid biology. John Wiley and Sons, New York, NY. p. $307-$ 330.

Barlow, P.W. and E.R. Hines. 1982. Regeneration of the root cap of Zea mays L. and Pisum sativum L.: A study with the scanning electron microscope. Ann. Bot. (Lond.) 49:521539

Barreto, D.W. and J.P. Parente. 2006. Chemical properties and biological activity of a polysaccharide from Cyrtopodium cardiochilum. Carbohydr. Polym. 64:287-291. 
Chen, J.T. and W.C. Chang. 2006. Direct somatic embryogenesis and plant regeneration from leaf explants of Phalaenopsis amabilis. Biol. Plant. 50:169-173.

Chugh, S., S. Guja, and I.U. Rao. 2009. Micropropagation of orchids: A review on the potential of different explants. Sci. Hort. 122:507-520.

Churchill, M.E., E.A. Ball, and J. Arditti. 1972. Tissue culture of orchids: II. Methods for root tips. Amer. Orchid Soc. Bul. 41:726-730.

Colli, S. and G.B. Kerbauy. 1993. Direct root tip conversion of Catasetum into protocorm-like bodies: Effects of auxin and cytokinin. Plant Cell Tiss. Org. Cult. 33:39-44.

Ernst, R. 1994. Effect of thidiazuron on in vitro propagation of Phalaenopsis and Doritaenopsis (Orchidaceae). Plant Cell Tiss. Org. Cult. 39:273-275.

Johansen, D.A. 1940. Plant microtechnique. McGraw Hill, New York, NY. p. 523.

Kerbauy, G.B. 1984. Plant regeneration of Oncidium varicosum (Orchidaceae) by means of root tip culture. Plant Cell Rep. 3: 27-29.

Kraus, J.E. and W.R. Monteiro. 1989. Formation of protocorm-like bodies from root apices of Catasetum pileatum (Orchidaceae) cultivated in vitro: I. Morphological aspects. Ann. Bot. (Lond.) 64:491-498.

Menezes, L.C. 1995a. Cyrtopodium in Brasil: Part 1. Introduction and five attractive species. Amer. Orchid Soc. Bul. 64:4-9.

Menezes, L.C. 1995b. Cyrtopodium in Brasil: Part 2. The yellow-flowered species. Amer. Orchid Soc. Bul. 64:248-251.

Murashige, T. and F. Skoog. 1962. A revised medium for rapid growth and bioassay with tobacco tissue cultures. Physiol. Plant. 15:473-497.

Park, S.Y., H.N. Murthy, and K.Y. Paek. 2003. Protocorm-like body induction and subsequent plant regeneration from root tip cultures of Doritaenopsis. Plant Sci. 164:919-923.

Pridgeon, A. 1998. The illustrated encyclopedia of orchids. Timber Press, Portland, OR. p. 84-85.
Rego-Oliveira, L.V. and R.T. Faria. 2005. In vitro propagation of Brazilian orchids using traditional culture media and commercial fertilizers formulations. Maringá 27:1-5.

Sánchez, M. 1988. Micropropagation of Cyrtopodium (Orchidaceae) through root-tip culture. Lindleyana 3:93-96.

Schneider, H. 1981. Plant anatomy and general botany, p. 315-333. In: Clark, G. (ed.). Staining procedures used by the Biological Stain Commission. Williams \& Wilkins, Baltimore, MD.

Steel, R.G.D., J.H. Torrie, and D.A. Dickey. 1997. Principles and procedures of statistics: A biometrical approach. 3rd Ed. McGraw-Hill, New York, NY.

Stewart, J. and J. Button. 1978. Development of callus and plantlets from Epidendrum root tips cultured in vitro. Amer. Orchid Soc. Bul. 47: 607-612.

Teng, W.L., L. Nicholson, and M.C. Teng. 1997. Micropropagation of Spathoglottis plicata. Plant Cell Rep. 16:831-835. 